\title{
Burmanniaceae e Gentianaceae da Usina São José, Igarassu, Pernambuco
}

\author{
Burmanniaceae and Gentianaceae of Usina São José, Igarassu, Pernambuco
}

\author{
Aline Melo ${ }^{1}$, Anderson Alves-Araújo ${ }^{1}$, Marccus Alves ${ }^{1,2}$
}

\begin{abstract}
Resumo
O objetivo deste trabalho é o estudo taxonômico das espécies de Burmanniaceae e Gentianaceae encontradas na Usina São José. As coletas foram realizadas em seis fragmentos florestais entre 2007 e 2009, além do levantamento dos herbários locais. Foram encontradas três espécies de Burmanniaceae: Apteria aphylla, Gymnosiphon divaricatus e G. sphaerocarpus; e quatro de Gentianaceae: Coutoubea spicata, Voyria caerulea, V. obconica e V. tenella. Apenas C. spicata é autótrofa; as demais são mico-heterótrofas. As espécies foram encontradas apenas nos maiores remanescentes e as espécies mico-heterótrofas mostraram-se potenciais bioindicadoras de ambientes conservados. Gymnosiphon sphaerocarpus constitui o primeiro registro para o Brasil.

Palavras-chave: Mata Atlântica, mico-heterótrofas, Nordeste do Brasil, saprófitas.
\end{abstract}

\begin{abstract}
A taxonomic study was made of Burmanniaceae and Gentianaceae from the Usina São José. Collecting was done in six forest fragments, from 2007 to 2009; vouchers from local herbaria were also studied. Three species of Burmanniaceae (Apteria aphylla, Gymnosiphon divaricatus, and G. sphaerocarpus) and four of Gentianaceae (Coutoubea spicata, Voyria caerulea, V. obconica, and V. tenella) were found. Only C. spicata is autotrophic, the others are myco-heterotrophic. Specimens were found only in the largest fragments and the myco-heterotrophs can be considered potential bioindicators of preserved environments. Gymnosiphon sphaerocarpus is recorded for the first time in Brazil.
\end{abstract}

Key-words: Atlantic rain forest, myco-heterotrophs, Northeastern Brazil, saprophytes.

\section{Introdução}

Mico-heterótrofas são plantas aclorofiladas que obtém nutrientes através da associação com fungos micorrízicos (Leake 1994). Podem ser geralmente encontradas no interior de florestas tropicais, sob o húmus (Maas et al. 1986b), entre outros tipos vegetacionais (Maas \& Ruyters 1986; Maas et al. 1986a,b; Leake 1994). Segundo FontQuer (1989), algumas mico-heterótrofas possuem folhas fotossintetizantes, sendo chamadas de mico-heterótrofas facultativas, como algumas espécies de Burmannia L. (Maas et al. 1986a). O termo "saprófita" é amplamente utilizado (Maas \& Ruyters 1986; Maas et al. 1986a,b; Maas \& Maas-van de Kamer 1997; Maas-van de Kamer \&
Maas 1997, 2002, 2003; Struwe et al. 1999; Caruzo \& Cordeiro 2000; Cordeiro \& Hoch 2005), mas incorretamente empregado segundo Leake (1994). Os fungos micorrízicos (que possuem associação com as plantas mico-heterótrofas) é que são os verdadeiros saprófitos, afinal são eles que metabolizam a matéria orgânica e disponibilizam os nutrientes para a planta (Maas et al. 1986b; Ribeiro et al. 1999).

Embora bastante peculiares, espécies micoheterótrofas podem ser encontradas em famílias de angiospermas não relacionadas filogeneticamente. No Brasil, elas estão representadas em Burmanniaceae, Gentianaceae, Orchidaceae e Triuridaceae (Souza \& Lorenzi 2008), mas não há registros dessas duas

1 Universidade Federal de Pernambuco, Centro de Ciências Biológicas, Depto. Botânica,Lab. Morfo-Taxonomia Vegetal, Av. Prof ${ }^{\circ}$ Moraes Rêgo s $/ n^{\circ}$, Cidade Universitária, 50670-901, Recife, PE, Brasil.

${ }^{2}$ Autor para correspondência. 
últimas famílias no Nordeste (Barbosa et al. 2006). O presente estudo é parte integrante de um amplo levantamento florístico nos fragmentos florestais da Usina São José e tem como objetivo o estudo taxonômico de Burmanniaceae e Gentianaceae na área. Apesar de serem famílias não relacionadas filogeneticamente (APG III 2009), elas são as únicas na área de estudo com representantes micoheterótrofos (Alves-Araújo et al. 2008).

Burmanniaceae (Dioscoreales) possui nove gêneros e cerca de 100 espécies e pode ser encontrada em regiões tropicais e temperadas (Henderson \& Stevenson 2004). No Brasil, ocorrem oito gêneros e cerca de 30 espécies (Souza \& Lorenzi 2008), nove delas listadas para o Nordeste (Conceição 2006; Maas-van de Kamer 2006). Oito gêneros são mico-heterótrofos (Burmannia L. é o único gênero com representantes mico-heterótrofos facultativos), sete deles ocorrendo no Brasil (Maas et al. 1986a; Leake 1994).

Gentianaceae (Gentianales) é constituída por 80 gêneros e cerca de 1.000 espécies, apresentando ampla distribuição (Struwe \& Albert 2004). No Brasil, foram registrados 28 gêneros e 100 espécies (Souza \& Lorenzi 2008), dos quais nove gêneros e 29 espécies estão citados para o Nordeste (Harvey 1995; Barbosa et al. 2004; Cordeiro 2006; Guimarães 2006). Quatro gêneros possuem representantes mico-heterótrofos, mas apenas Voyria Aubl. e Voyriella (Miq.) Miq ocorrem no Brasil (Maas \& Ruyters 1986).

\section{Materiais e Métodos}

A Usina São José (USJ) localiza-se no litoral norte de Pernambuco, a cerca de $40 \mathrm{~km}$ de Recife (7०40'21,25"-755'50,92"S, 3454'14,25"$\left.35^{\circ} 05^{\prime} 21,08^{\prime \prime} \mathrm{W}\right)$, com área total de $280 \mathrm{~km}^{2}$; sua maior parte encontra-se no município de Igarassu, mas abrange também Abreu e Lima, Araçoiaba, Goiana, Itapissuma e Itaquitinga (Trindade et al. 2008). Situada em área de Mata Atlântica, está entre as usinas que possuem os maiores remanescentes e maior área absoluta de floresta atlântica ao norte do São Francisco (Uchôa Neto \& Tabarelli 2002) e, segundo Veloso et al. (1991), possui vegetação de Floresta Estacional Semidecidual de Terras Baixas. Embora seja considerada de "Extrema
Importância Biológica”, segundo o MMA (2000), possui apenas uma área de proteção, conhecida como Reserva Ecológica da Mata da Usina São José ou Mata de Piedade. A área possui 306 ha em bom estado de conservação (Trindade et al. 2008) e é protegida pela Lei Estadual n ${ }^{\circ} 9.989$ de 1987 (Santos et al. 2001).

A área da USJ possui 110 fragmentos de floresta atlântica com diferentes dimensões e formas; seis deles foram selecionados para o presente estudo: Macacos - 357 ha, Pezinho - 29 ha, Piedade - 306 ha, Santa Helena - 12 ha, Vespas- 14 ha e Zambana - 388 ha (Trindade et al. 2008). Foram realizadas coletas mensais, 2-4 dias, entre março de 2007 e março de 2009, com maior intensidade no período chuvoso (janeiro a abril). O material foi coletado exclusivamente em estado fértil e submetido às técnicas usuais (Mori et al. 1985). Os vouchers foram depositados no herbário UFP.

Foi realizado o levantamento das amostras de ambas as famílias depositadas nos herbários HST, IPA, PEUFR e UFP (siglas segundo Thiers 2009). As identificações foram realizadas com apoio de bibliografia específica (Maas \& Ruyters 1986; Maas et al. 1986a,b; Maas \& Maas-van de Kamer 1997; Maas-van de Kamer \& Maas 1997, 2002, 2003; Struwe et al. 1999; Caruzo \& Cordeiro 2000; Cordeiro \& Hoch 2005) e comparação com materiais de referência. São apresentadas chave de identificação, descrições e ilustrações dos caracteres macromorfológicos diagnósticos das espécies registradas na área.

\section{Resultados e Discussão}

Na Usina São José, foram encontradas sete espécies pertencentes às duas famílias, sendo três em Burmanniaceae: Apteria aphylla (Nutt.) Barnhart ex Small, Gymnosiphon divaricatus (Benth.) Benth. \& Hook. e G. sphaerocarpus Urb., e quatro em Gentianaceae: Coutoubea spicata Aubl., Voyria caerulea Aubl., V. obconica Progel e $V$. tenella Hook. Seis delas são mico-heterótrofas, sendo apenas Coutoubea spicata autótrofa. As espécies mico-heterótrofas foram encontradas apenas no interior dos maiores remanescentes, mostrando-se potenciais bioindicadoras de ambientes conservados. 


\section{Tratamento Taxonômico}

\section{Chave de identificação para as Burmanniaceae e Gentianaceae da Usina São José}

1. Ervas mico-heterótrofas; flores trímeras, homoclamídeas Burmanniaceae

2. Flores lilás, perigônio campanulado

2'. Flores alvas, perigônio infundibuliforme 1. Apteria aphylla

3. Comprimento da cápsula menor que o do tubo floral persistente Gymnosiphon

3'. Comprimento da cápsula maior que o do tubo floral persistente 2. G. divaricatus

1'. Ervas autótrofas ou mico-heterótrofas; flores tetrâmeras ou pentâmeras, heteroclamídeas ..... Gentianaceae 4. Ervas autótrofas; flores tetrâmeras 4. Coutoubea spicata

4'. Ervas mico-heterótrofas; flores pentâmeras Voyria

5. Inflorescência umbeliforme, brácteas e bractéolas presentes; flores 15-35 mm compr. ......... 5. V. caerulea

5'. Flores solitárias, brácteas e bractéolas ausentes; flores 8-17 mm compr.

6. Flores $10-17 \mathrm{~mm}$ compr., lilás a roxas 6. V. obconica

6'. Flores 8-10 mm compr., amarelas a alaranjadas 7. V. tenella

\section{Burmanniaceae Blume}

Ervas anuais ou perenes, mico-heterótrofas facultativas ou não, geralmente não ramificadas, glabras. Rizoma cilíndrico, escamoso. Folhas alternas, simples, sésseis, freqüentemente escamiformes, uninérveas ou paralelinérveas, margem inteira, estípulas ausentes. Inflorescência cimosa ou racemosa, brácteas presentes. Flores pouco vistosas, actinomorfas, bissexuadas ou unissexuadas, trímeras, monoclamídeas ou diclamídeas, homoclamídeas ou heteroclamídeas, cálice e corola geralmente unidos entre si; 3 estames, livres ou unidos entre si; anteras rimosas; nectários geralmente presentes; gineceu sincárpico; ovário ínfero, tricarpelar, unilocular ou trilocular, pluriovulado, placentação axial ou parietal; estilete único. Fruto cápsula, freqüentemente alado.

Burmanniaceae possui distribuição pantropical (Maas et al. 1986b). Para o Nordeste, são registrados cinco gêneros e nove espécies (Conceição 2006; Maas-van de Kamer 2006), sendo Burmannia o gênero mais representativo, com cinco espécies.

\section{Apteria Nutt.}

Esse gênero é monotípico, incluindo apenas Apteria aphylla, que ocorre no sudeste dos Estados Unidos, México, América Central, Antilhas, Colômbia, Venezuela, Trindade, Guiana, Suriname, Guiana Francesa, Equador, Peru, Bolívia, Paraguai e Brasil (Maas \& Maas-van de Kamer 1997).
1. Apteria aphylla (Nutt.) Barnhart ex Small., Fl. s.e. U.S.: 309. 1903.

Figs. 1a-c, 3a-d

Ervas anuais, 7,5-24 cm alt., micoheterótrofas, lilás, não ramificadas. Folhas 1-2,5× 0,5-1 mm, escamiformes, uninérveas, lineares, ápice agudo. Inflorescência em racemo, 1-6-flora, brácteas 1-2,5 $\mathrm{mm}$ compr., estreitamente lanceoladas, ápice agudo. Flores 4-10 mm compr., lilás, pediceladas, bissexuadas, homoclamídeas; perigônio campanulado; as 3 tépalas externas mais largas que as 3 internas, triangulares, ápice agudo; as internas filiformes, ápice agudo; estames 3, livres entre si, adnatos às tépalas; ovário 1-3,5 mm compr., unilocular; estigma amarelo, tripartido, caliciforme a dentado. Fruto 3-5×1-3 mm, elipsóide a globóide. Sementes globosas, diminutas.

Material selecionado: Mata dos Macacos, 22.VII.2008, fl., A. Melo et al. 308 (UFP); Mata de Piedade, 24.V.2008, fl. e fr., A. Melo et al. 294 (UFP); Mata da Zambana, 28.VII.2007, fl. e fr., A. Melo et al. 101 (UFP).

Material adicional: BRASIL. PERNAMBUCO: Recife, Dois Irmãos, Parque Estadual de Dois Irmãos, V.1995, fl. e fr., M. Alves 395 (UFP); Jaboatão dos Guararapes, Reserva Florestal do Curado, 25.X.1967, fl. e fr., O. C. Lira 118-1967 (UFP).

No Nordeste, há registros para a Chapada Diamantina-Bahia (Maas 1995; Queiroz et al. 2005) e o semi-árido (Conceição 2006). Ocorre freqüentemente em áreas sazonalmente alagadas, no interior da mata, sendo de fácil identificação por toda a planta, inclusive o caule, possuir coloração lilás e a corola ser campanulada. 
Gymnosiphon Blume.

Ervas anuais, mico-heterótrofas, pardas, ramificadas ou não. Folhas escamiformes, uninérveas. Inflorescência terminal, bifurcada, com muitas flores ou apenas uma flor. Flores alvas, pediceladas, bissexuadas, homoclamídeas; perigônio infundibuliforme; as 3 tépalas externas trilobadas (1 central e 2 laterais), maiores que as 3 internas; as internas pequenas, inseridas no tubo floral, abaixo da inserção das tépalas externas; estames livres entre si; ovário unilocular. Fruto globóide a elipsóide. Sementes globosas, com uma projeção aguda.

Possui distribuição pantropical e 25 espécies; 14 delas podem ser encontradas nos Neotrópicos (Mass et al. 1986a). Para o Nordeste, era registrada apenas G. divaricatus (Maas-van de Kamer 2006; Amorim et al. 2008).

2. Gymnosiphon divaricatus (Benth.) Benth. \& Hook. f., Gen. pl.3(2): 458. 1883. Figs. 1 d-g, 3 e-h Ervas, $10-25 \mathrm{~cm}$ alt. Folhas $1-2 \times 0,2-0,5 \mathrm{~mm}$, lanceoladas, ápice agudo a obtuso. Inflorescência cimeira monocasial, brácteas $1-1,5 \mathrm{~mm}$ compr. Flores 4-7 mm compr.; tépalas externas centrais triangulares, as laterais lineares a triangulares; tépalas internas lanceoladas; ovário 1-2 mm compr.; estilete 3-6 mm compr., persistente, visível no fruto; estigma amarelo, tripartido com apêndices filiformes. Fruto 1,5-2 ×1-2 mm, pardo, opaco.

Material selecionado: Mata da Usina São José, 1971, f1. e fr., D. Andrade-Lima et al. 71-6457 (IPA); 26.VI.1955, fl. e fr., D. Andrade-Lima et al. 55-2089 (IPA- PEUFR); Mata dos Macacos, 15.VI.2007, fl. e fr., A. Melo et al. 90 (UFP); Mata de Piedade, 29.VII.2007, fl. e fr., A. Melo et al. 114 (UFP); Mata da Zambana, 4.IX.2007, fl. e fr., A. Melo et al. 126 (UFP).

Encontra-se distribuída na América Central e América do Sul (Maas et al. 1986a). No Nordeste, já havia sido registrada para a Bahia (Amorim et al. 2008). Pode ser confundida com G. sphaerocarpus, porém seu tubo floral persistente é mais comprido que a cápsula, enquanto em G. sphaerocarpus o comprimento da cápsula é maior que o do tubo floral. Nas amostras de herbário, a coloração da cápsula torna-se escura. Em campo, o estigma amarelo tripartido é de fácil visualização, mas pode ser identificada também pela inflorescência e as cápsulas de coloração parda e opaca.

3. Gymnosiphon sphaerocarpus Urb., Symb. antill. 3(3): 442.1903.

Fig. 1 h-i

Ervas, 11-25 cm alt. Folhas 0,5-1,5 mm, lineares a lanceoladas, ápice obtuso. Inflorescência paniculóide, brácteas < $1 \mathrm{~mm}$ compr. Flores 2,5-4 mm compr.; tépalas externas centrais triangulares; tépalas internas estreitamente obovada; ovário 11,5 mm compr.; estilete $2-3 \mathrm{~mm}$ compr., persistente; estigma capitado. Fruto 1,5-2 $\times 1-1,5 \mathrm{~mm}$, pardo a alvo, brilhante.

Material examinado: Mata de Piedade, 29.VII.2007, fl. e fr., A. Melo et al 113 (UFP).

Segundo Maas et al. (1986a), G. sphaerocarpus tem distribuição restrita às Antilhas Caribenhas: Cuba, Dominica, Guadalupe, Jamaica, Porto Rico e República Dominicana. Apresenta-se aqui o primeiro registro extra-caribenho para esta espécie, marcando uma nova ocorrência para o Brasil. Considerada rara na área de estudo, foi encontrada em apenas um dos fragmentos florestais.

\section{Gentianaceae Juss.}

Ervas anuais ou perenes, mico-heterótrofas (pardas) ou autótrofas (verdes), subarbustos, raramente arbustos ou pequenas árvores. Caule cilíndrico. Folhas opostas, verticiladas ou alternas, simples, margem inteira, estípulas ausentes. Inflorescência cimosa ou raramente racemosa, às vezes reduzida a uma única flor. Flores vistosas, bissexuadas, actinomorfas ou zigomorfas, tetrâmeras ou pentâmeras, diclamídeas; cálice gamossépalo; corola gamopétala; androceu isostêmone, estames alternipétalos, epipétalos, inseridos no tubo ou nos lobos da corola; anteras rimosas ou poricidas; nectários geralmente presentes; ovário súpero, bicarpelar, unilocular ou bilocular, pluriovulado, placentação parietal; estilete único. Fruto cápsula.

Gentianaceae possui ampla distribuição mundial (Struwe \& Albert 2004). No Nordeste, há registros de 29 espécies e nove gêneros (Harvey 1995; Barbosa et al. 2004; Cordeiro 2006; Guimarães 2006), sendo Schultesia Roth. e Voyria os maiores, com nove e seis espécies, respectivamente. Guedes (1998), Maas (1998), Harley et al. (2005) e Amorim et al. (2008) citaram representantes para os estados da Bahia e Pernambuco. Na área de estudo, foram encontrados Coutoubea Aubl. e Voyria (Alves-Araújo et al. 2008), sendo este último mico-heterótrofo.

\section{Coutoubea Aubl.}

Ervas anuais ou perenes, autótrofas (coloração verde), ramificadas ou não. Folhas opostas, sésseis ou levemente pediceladas. Inflorescência terminal, racemosa ou espiga congesta, por vezes ramificada. Flores actinomorfas, tetrâmeras ou pentâmeras, 


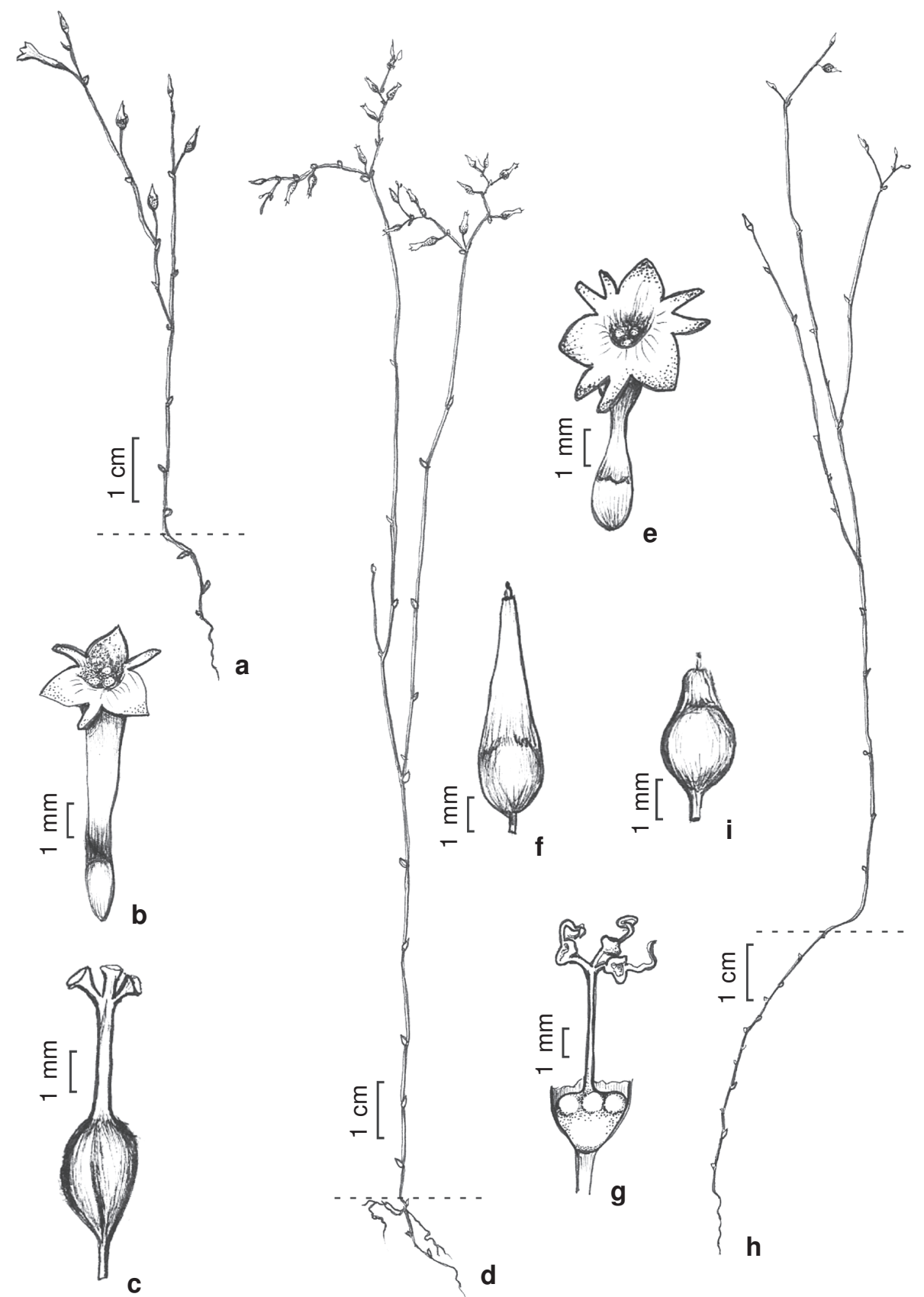

Figura 1 - Burmanniaceae - a linha pontilhada indica a separação entre a porção subterrânea e aérea - a-c. Apteria aphylla - a. hábito; b. flor; c. gineceu, evidenciando o estigma tripartido. d-g. Gymnosiphon divaricatus - d. hábito; e. flor; f. fruto (cápsula), evidenciando a proporção do fruto em relação ao tubo floral persistente; g. gineceu, evidenciando o estigma tripartido com apêndices filiformes. h-i. Gymnosiphon sphaerocarpus - h. hábito; i. fruto (cápsula), evidenciando o maior comprimento em relação ao tubo floral persistente. (a-c Melo 101; d-g Melo 90; h-i Melo 113). Figure 1 - Burmanniaceae - the dashed line indicates the distinction between the underground and aerial organs - a-c. Apteria aphylla - a. habit; b. flower; c. gynoecium, showing the tripartite stigma. d-g. Gymnosiphon divaricatus - d. habit; e. flower; f. fruit (capsule), showing the proportion of the fruit in relation to the persistent floral tube; g. gynoecium, showing the tripartite stigma with filiform appendages. h-i. Gymnosiphon sphaerocarpus - h. habit; i. fruit (capsule) exserted beyond the persistent floral tube. (a-c Melo 101; d-g Melo 90; h-i Melo 113). 
sésseis ou com pequeno pedicelo; cálice campanulado a tubular, persistente no fruto; corola geralmente salveforme, persistente no fruto.

Coutoubea possui oito espécies e está representada em Belize, Brasil, Colômbia, Costa Rica, Guadalupe, Guatemala, Guiana, Guiana Francesa, México, Panamá, Peru, São Vicente, Suriname, Venezuela, Trindade e Tobago (Struwe et al. 1999). Para o Nordeste, há registros de duas espécies: Coutoubea spicata e C. ramosa Aubl. (Cordeiro 2006; Guimarães 2006).

4. Coutoubea spicata Aubl., Hist. pl. Guiane 1: 72; tab. 27. 1775 (non Griseb.).

Fig. $2 \mathrm{a}-\mathrm{b}$

Ervas perenes, 0,3-1 $\mathrm{m}$ alt., ramificadas ou não. Caule cilíndrico. Folhas 3-9 ×1-2 cm, opostas, sésseis, lanceoladas, peninérveas, base obtusa, ápice agudo, glabras. Inflorescência $2-10 \mathrm{~cm}$ compr., espiciforme ou panícula de espigas. Flores tetrâmeras, 6-7 cm compr., alvas; cálice tubular, lobos verdes que acompanham todo o comprimento do tubo floral; corola infundibuliforme a salveforme, lobos isomorfos; estames exsertos; ovário 3-5 mm compr., elipsóide, unilocular; estigma bilobado, área estigmática capitada. Fruto 7-10×3-5 mm, ovóide, ápice agudo.

Material selecionado: Mata dos Macacos, 19.XII.2007, fl., N. A. Albuquerque et al. 618 (IPA); Mata de Piedade, 10.IX.2008, fl., A. Melo et al. 327 (UFP); Mata da Zambana, 28.VII.2007, fl., A. Melo et al. 129 (UFP).

Coutoubea spicata está distribuída ao longo da América Central, Colômbia, Guiana, Guiana Francesa, Peru e Brasil (Struwe et al. 1999). Pode ser encontrada em bordas de florestas, formações florestais secundárias e na margem das estradas (Struwe et al. 1999; Maas-van de Kamer \& Maas 2002). Amplamente encontrada nos maiores fragmentos, pode ser reconhecida pela inflorescência, cor das flores e limbo foliar expandido, sendo a única espécie clorofilada da família na área de estudo.

\section{Voyria Aubl.}

Ervas anuais, mico-heterótrofas, pardas, não ramificadas. Rizoma tuberoso. Caule cilíndrico. Folhas escamiformes, opostas, conadas, glabras. Flores em inflorescência ou solitárias, brácteas e bractéolas presentes ou não. Flores actinomorfas, pentâmeras, pediceladas; cálice tubular; corola salveforme, lobos inteiros e isomorfos; estames inclusos, eretos.

Voyria possui 19 espécies, sendo 18 neotropicais e uma do oeste da África (Maas \& Ruyters 1986).
No Nordeste, estão catalogadas seis espécies (Barbosa et al. 2004; Cordeiro 2006; Guimarães 2006): V. aphylla (Jacq.) Pers., V. flavescens Griseb. e V. parasitica (Schltdl. \& Cham.) Ruyters \& Maas; além das três espécies encontradas na área de estudo: V. caerulea, $V$. obconica e $V$. tenella.

5. Voyria caerulea Aubl., Hist. pl. Guiane 1: 211; tab. 83, fig. 2. 1775.

Fig. 2 c-d

Ervas, ca. $12 \mathrm{~cm}$ alt. Folhas $4-5 \times 2-3 \mathrm{~mm}$, lanceoladas, base obtusa, ápice agudo. Inflorescência umbeliforme, 7-flora, bráctea ca. $5 \mathrm{~mm}$ compr., lanceolada, bractéolas 5-8 mm compr., lanceoladas, ápice agudo, envolvendo o cálice. Flores 15-35 mm compr., azuis a lilás, porção inferior do tubo da corola até $2 \mathrm{~cm}$ compr., porção superior até $8 \mathrm{~mm}$ compr., lobos até $6 \mathrm{~mm}$ compr., lanceolados, ápice obtuso; sépalas 10-20 mm compr., oblanceoladas a lanceoladas, ápice obtuso; ovário ca. 10 mm compr., estigma em forma de funil. Fruto não observado. Material examinado: Mata da Usina São José, 26.VI.1955, fl., D. Andrade-Lima et al. 55-2090 (PEUFR).

Ocorre no Brasil, Guiana, Guiana Francesa, Suriname e Venezuela (Maas \& Ruyters 1986). A espécie só possui um registro para o Nordeste, no semi-árido (Cordeiro 2006), sendo aqui o seu primeiro registro para Pernambuco. Conhecida exclusivamente por material de herbário, não tendo sido recentemente recoletada. Diferencia-se das demais espécies do gênero na área de estudo por apresentar flores reunidas em inflorescência, acompanhadas de brácteas e bractéolas.

6. Voyria obconica Progel in Mart., Fl. bras. 6(1): 221; tab. 60, fig. 5. 1865.

Fig. 2 e-g, 3 i-1

Ervas, 7-14 cm alt. Folhas 3-6 × 1-2 mm, triangulares, base obutsa, ápice agudo. Flores solitárias (sem brácteas, nem bractéolas), 10-17 mm compr., lilás a roxas, com faixas brancas desde a base dos lobos até o ápice, porção inferior do tubo da corola 8-12 mm compr., porção superior até $4 \mathrm{~mm}$ compr., lobos da corola 4-8 mm compr., obovados, base pilosa, ápice obtuso; sépalas 4-8 mm compr., oblongas a elípticas, ápice obtuso; ovário 6-12 mm compr., estigma discóide. Fruto 1,2-1,5 cm compr., elipsóide; sementes numerosas, $<1 \mathrm{~mm}$ compr., levemente arredondadas na base, ápice acuminado. Material selecionado: Mata dos Macacos, 15.VIII.2007, fl., A. Alves-Araújo et al. 527 (UFP); Mata de Piedade, 29.VII.2007, fl. e fr., A. Melo et al. 116 (IPA, UFP).

É encontrada no leste e sudeste do Brasil (Maas \& Ruyters 1986), rendo sido registrada também para 


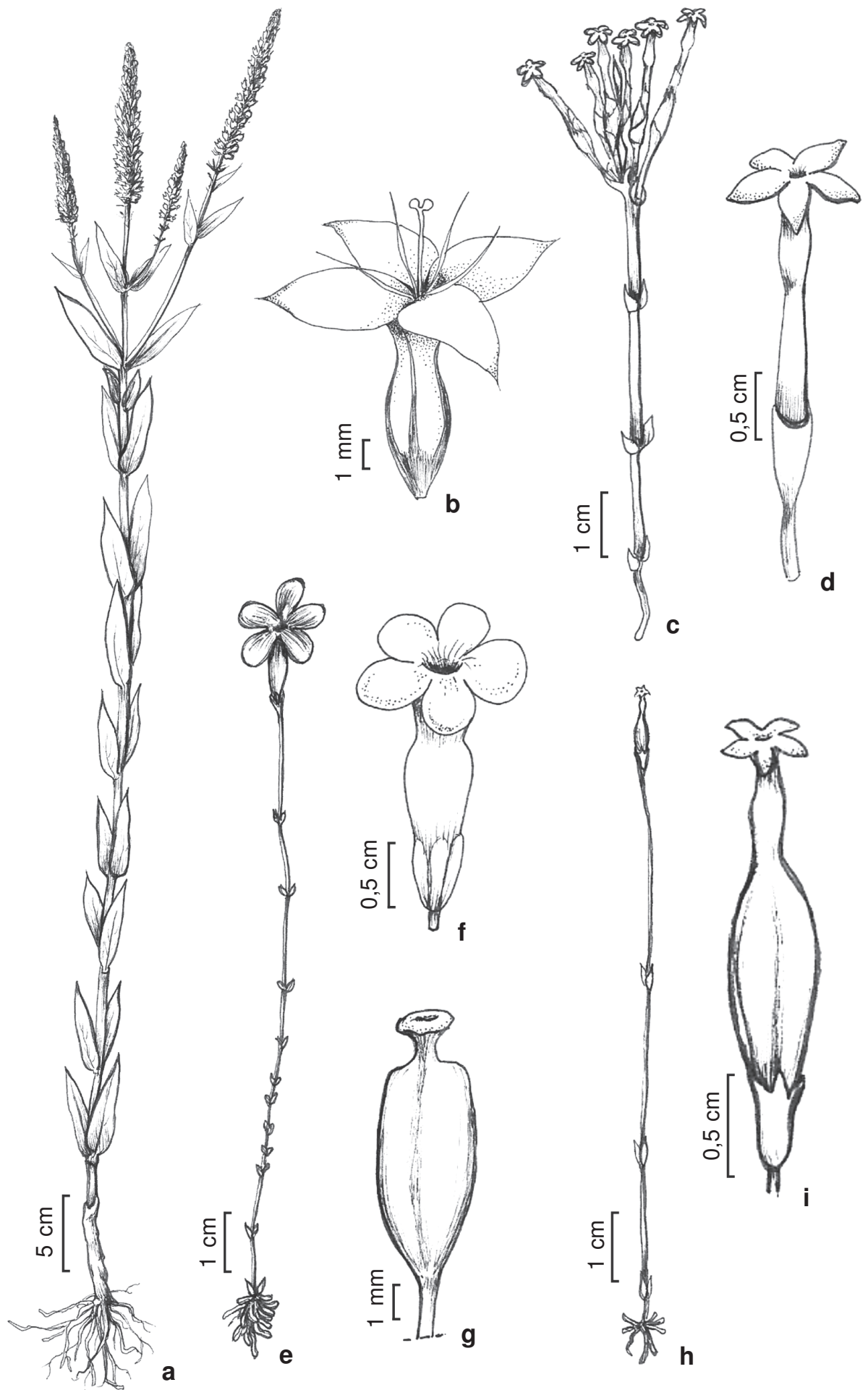

Figura 2 - Gentianaceae - a-b. Coutoubea spicata - a. hábito evidenciando inflorescências compostas e simples; b. flor. c-d. Voyria caerulea - c. hábito; d. flor. e-g. Voyria obconica - e. hábito; f. flor; g. gineceu evidenciando o estigma discóide. h-i. Voyria tenella - h. hábito, i. flor. (a-b Melo 129; c-d Andade-Lima 55-2090; e-g Melo 116; h-i Andrade-Lima 71-6456). Figure 2 - Gentianaceae - a-b. Coutoubea spicata - a. habit showing compound and simple inflorescences; b. flower. c-d. Voyria caerulea - c. habit; d. flower. e-g. Voyria obconica - e. habit; f. flower; g. gynoecium showing the discoid stigma. h-i. Voyria tenella - h. habit; i. flower. (a-b Melo 129; c-d Andrade-Lima 55-2090; e-g Melo 116; h-i Andrade-Lima 71-6456). 

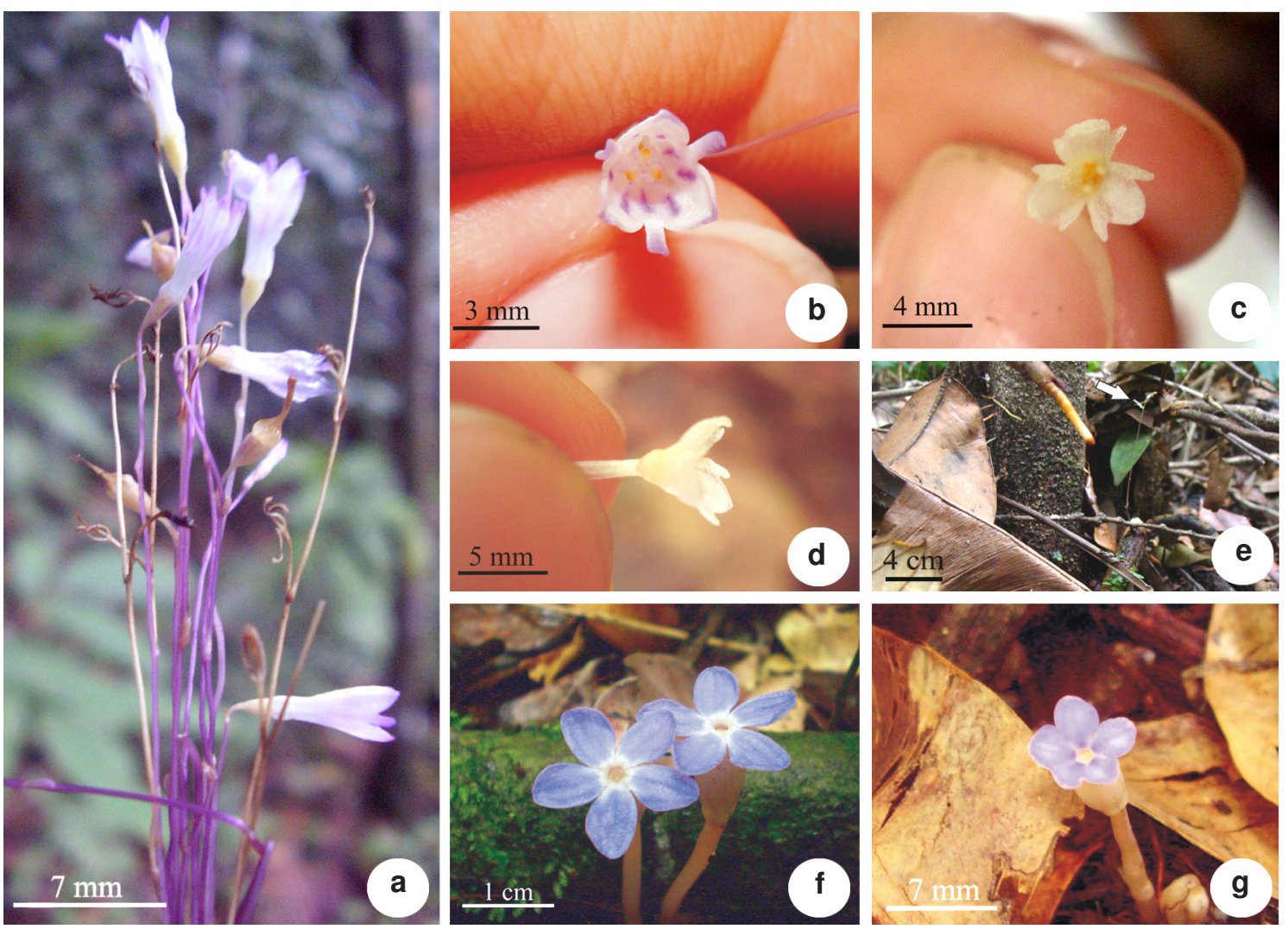

Figura 3 - a-b. Apteria aphylla - a. hábito; b. flor evidenciando estigma tripartido. c-e. Gymnosiphon divaricatus c. flor evidenciando estigma e formato das tépalas; d. flor; e. hábito: indivíduo indicado com seta, sob o húmus da floresta. f-g. Voyria obconica -f. hábito; g. indivíduo em floração. (a-b Melo 308; c-e Melo 312; f-g Melo 116).

Figure 3 - a-b. Apteria aphylla - a. habit; b. flower showing the stigma and shape of the petals. c-e. Gymnosiphon divaricatus c. yellow flower with stigma and shape of petals visible; d. flower; e. habit: specimen indicated by arrow in the humus of the forest. f-g. Voyria obconica - f habit; g. specimen blooming. (a-b Melo 308; c-e Melo 312; f-g Melo 116).

o sul da Bahia (Amorim et al. 2008). Diferencia-se de $V$. caerulea por apresentar flores solitárias e de $V$. tenella por possuir flores lilás. A flor contrasta com a coloração da serrapilheira em decomposição e possui odor agradável.

7. Voyria tenella Guild. ex Hook., Bot. Misc. 1: 47; tab. 25, fig. B. 1830.

Fig. 2 h-i

Ervas, $8-17 \mathrm{~cm}$ alt. Folhas $3-5 \times 0,5-1 \mathrm{~mm}$, oblanceoladas, base aguda, ápice atenuado. Flores solitárias (sem brácteas, nem bractéolas), 8-10 mm compr., amarelas a alaranjadas, porção inferior do tubo da corola 5-8 mm compr., porção superior 2$4 \mathrm{~mm}$ compr., lobos até $2 \mathrm{~mm}$ compr., lanceolados, ápice levemente agudo; sépalas 2-4 mm compr., lanceoladas, ápice obtuso; ovário 4-6 mm compr., estigma capitado. Fruto ca. $5 \times 3 \mathrm{~mm}$, elipsóide; sementes até $1 \mathrm{~mm}$ compr., filiformes.
Material examinado: Mata da Usina São José, 1971, fl. e fr., D. Andrade-Lima et al. 71-6456 (IPA).

Material adicional: BRASIL. PERNAMBUCO: Recife, Dois Irmãos, Parque Estadual de Dois Irmãos, 1.IX.1949, fl. e fr., D. Andrade-Lima 49-287 (IPA).

Possui distribuição neotropical (Maas \& Ruyters 1986) e, assim como V. caerulea, não foi recoletada na área. Pode ser facilmente identificada pelo espessamento da porção inferior do tubo da corola, pétalas menores e as flores amarelas.

\section{Agradecimentos}

Ao CNPq, a bolsa concedida; aos curadores dos herbários HST, IPA, PEUFR e UFP, o espaço cedido para consulta à coleção botânica; à equipe do Projeto Fragmentos e à ilustradora Regina Carvalho; à Dra. Elsie Guimarães, pelo suporte nas identificações. Este trabalho contou com apoio financeiro do $\mathrm{BMBF} / \mathrm{CNPq}$. 


\section{Referências}

Alves-Araújo, A.; Araújo, D.; Marques, J.; Melo, A.; Maciel, J.R.; Irapuan, J.; Pontes, T.; Lucena, M.F.A.; Bocage, A.L. \& Alves, M. 2008. Diversity of angiosperms in fragments of Atlantic forest in the State of Pernambuco, Northeastern Brazil. Bioremediation, Biodiversity and Bioavailability 2: 14-26.

Amorim, A.M.; Thomas, W.W.; Carvalho, A.M.V. \& Jardim, J.G. 2008. Floristics of the Una Biological Reserve, Bahia, Brazil. In: Thomas, Wm.W. \& Britton, E.G. (eds.). The Atlantic Coastal Forest of Northeastern Brazil. The New York Botanical Garden, New York. Pp. 67-146.

Angiosperm Phylogeny Group (APG III). 2009. An update of the Angiosperm Phylogeny Group classification for the orders and families of flowering plants: APG III. Botanical Journal of the Linnean Society 161: 105-121.

Barbosa, M.R.V.; Agra, M.F.; Sampaio, E.V.S.B.; Cunha, J.P. \& Andrade, L.A. 2004. Diversidade florística na Mata do Pau-Ferro, Areia, Paraíba. In: Porto, K.C.; Cabral, J.J.P. \& Tabarelli, M. (orgs.). Brejos de altitude em Pernambuco e Paraíba: História natural, ecologia e conservação. Biodiversidade 9. Ministério do Meio Ambiente, Brasília-DF. Pp. 111-122.

Barbosa, M.R.V.; Sothers, C.; Mayo, S.; Gamarra-Rojas, C.F.L. \& Mesquita, A.C. 2006. Checklist das plantas do Nordeste brasileiro: angiospermas e gymnospermas. Ministério de Ciência e Tecnologia, Brasília. 156p.

Barros, F. \& Felix, L.P. 2006. Orchidaceae. In: Barbosa, M.R.V.; Sothers, C.; Mayo, S.; Gamarra-Rojas, C.F.L. \& Mesquita, A.C. (orgs.). Checklist das plantas do Nordeste brasileiro: Angiospermas e gymnospermas. Ministério de Ciência e Tecnologia, Brasília. Pp. 149-162.

Caruzo, M.B.R. \& Cordeiro, I. 2000. Gentianaceae. In: Melo, M.M.R.F.; Barros, F.; Chiea, S.A.C.; Kirizawa, M.; Jung-Mendaçolli, S.L. \& Wanderley, M.G.L. (eds.). Flora fanerogâmica da Ilha do Cardoso. Vol. 7. Instituto de Botânica, São Paulo. Pp. 93-98.

Conceição, A.A. 2006. Burmanniaceae. In: Giulietti, A.M.; Conceição, A.A. \& Queiroz, L.P. (eds.). Diversidade e caracterização das fanerógamas do semi-árido brasileiro. Vol. 1. Associação de Plantas do Nordeste, Recife. Pp. 78-79.

Cordeiro, I. 2006. Gentianaceae. In: Giulietti, A.M.; Conceição, A.A. \& Queiroz, L.P. (eds.). Diversidade e caracterização das fanerógamas do semi-árido brasileiro. Giulietti, A.M. \& Queiroz, L.P. (orgs.). Instituto do Milênio do Semi-árido. Vol. 1. Associação de Plantas do Nordeste, Recife. Pp. 116-117.

Cordeiro, I. \& Hoch, A.M. 2005. Gentianaceae. In: Wanderley, M.G.L.; Shepherd, G.J.; Melhem, T. S.A.; Martins, S.E.; Giulietti, A.M. \& Kirizawa,
M. (eds.). Flora fanerogâmica do estado de São Paulo. Vol. 4. Rima, São Paulo. Pp. 211-222.

Font-Quer, P. 1989. Diccionario de botánica. $10^{\mathrm{a}} \mathrm{ed}$. Labor, Barcelona. 1244p.

Guedes, M.L.S. 1998. A vegetação fanerogâmica da Reserva Ecológica de Dois Irmãos. In: Machado, I.C.; Lopes, A.V. \& Porto, K.C. (orgs.). Reserva Ecológica de Dois Irmãos: estudos em um remanescente de Mata Atlântica em área urbana (Recife-Pernambuco-Brasil). Ed. UniversitáriaUFPE, Recife. Pp. 157-172.

Guimarães, A.F. 2006. Gentianaceae. In: Barbosa, M. R.V.; Sothers, C.; Mayo, S.; Gamarra-Rojas, C.F.L. \& Mesquita, A.C. (orgs.). Checklist das plantas do Nordeste brasileiro: angiospermas e gymnospermas. Ministério de Ciência e Tecnologia, Brasília. 75p.

Harley, R.M.; Giulietti, A.M.; Grilo, A.S.; Silva, T.R.S.; Funch, L.; Funch, R.R.; Queiroz, L.P.; França, F.; Melo, E.; Gonçalves, C.N. \& Nascimento, F.H.F. 2005. Cerrado. In: Juncá, F.A.; Funch, L. \& Rocha, W. (orgs.). Biodiversidade e conservação da Chapada Diamantina. Biodiversidade 13. Ministério do Meio Ambiente, Brasília. Pp. 121-152.

Harvey, Y.B. 1995. Gentianaceae. In: Stannard, B.L. (ed.). Flora of the Pico das Almas, Chapada Diamantina, Bahia, Brazil. Royal Botanic Gardens, Kew. Pp. 321-327.

Henderson, A. \& Stevenson, D. Wm. 2004. Burmanniaceae. In: Smith, N.; Mori, S.A.; Henderson, A.; Stevenson, D.Wm. \& Heald, S.V. (eds.). Flowering plants of the Neotropics. Princeton University press, Princeton. Pp. 421-423.

Leake, J.R. 1994. The biology of myco-heterotrophic ("saprophytic") plants. New Phytologist 127: 171-216.

Maas, P.J.M. 1995. Burmanniaceae. In: Stannard, B.L. (ed.). Flora of the Pico das Almas, Chapada Diamantina, Bahia, Brazil. Royal Botanic Gardens, Kew. Pp. 659-660.

Maas, P.J.M. 1998. Gentianaceae. In: Sales, M.F.; Mayo, S.J. \& Rodal, M.J.N. (eds.). Plantas vasculares das florestas serranas de Pernambuco: Um checklist da flora ameaçada dos Brejos de Altitude, Pernambuco- Brasil. Universidade Federal de Pernambuco, Recife. P. 67.

Maas, P.J.M. \& Maas-van de Kamer, H. 1997. Burmanniaceae. In: Berry, P.E; Holst, B.K. \& Yatskievych, K. (eds.). Flora of the Venezuelan Guayana. Vol. 3. Missouri Botanical Garden, Saint Louis. Pp. 678-688.

Maas, P.J.M. \& Ruyters, P. 1986. Voyria and Voyriella (Saprophytic Gentianaceae). Flora Neotropica 41: 1-93.

Maas, P.J.M.; Maas-van de Kamer, H.; Benthem, J.; Snelders, H.C.M. \& Rübsamen, T. 1986a. Burmanniaceae. Flora Neotropica 42: 1-189.

Maas, P.J.M.; Maas-van de Kamer, H.; Benthem, J.; Snelders, H.C.M.; Rübsamen, T. \& Ruyters, P. 1986b. Saprophytes pro parte. Flora Neotropica 40-42: 1-5. 
Maas-van de Kamer, H. 2006. Burmanniaceae. In: Barbosa, M.R.V.; Sothers, C.; Mayo, S.; GamarraRojas, C.F.L. \& Mesquita, A.C. (orgs.). Checklist das plantas do Nordeste brasileiro: angiospermas e gymnospermas. Ministério de Ciência e Tecnologia, Brasília. P. 53.

Maas-van de Kamer, H. \& Maas, P.J.M. 1997. Burmanniaceae. In: Mori, S.A.; Cremers, G.; Gracie, C.A.; Granville, J.-J.; Hoff, M. \& Mitchell, J.D. (eds.). Guide to the vascular plants of Central French Guiana: Part 1. Pteridophytes, gymnosperms, and monocotyledons. The New York Botanical Garden, New York. Pp. 232-237.

Maas-van de Kamer, H. \& Maas, P.J.M. 2002. Gentianaceae. In: Mori, S.A.; Cremers, G.; Gracie, C.A.; Granville, J.-J.; Heald, S.V.; Hoff, M. \& Mitchell, J.D. (eds.). Guide to the vascular plants of Central French Guiana: Part 2. Dicotyledons. The New York Botanical Garden, New York. Pp. 328-334.

Maas-van de Kamer, H. \& Maas, P.J.M. 2003. Burmanniaceae. In: Wanderley, M.G.L.; Shepherd, G.J.; Melhem, T.S.A.; Giulietti, A.M. \& Kirizawa, M. (eds.). Flora fanerogâmica do estado de São Paulo. Vol.3. Rima, São Paulo. Pp. 1-7.

MMA - Ministério do Meio Ambiente. 2000. Avaliação e ações prioritárias para a conservação da biodiversidade da Mata Atlântica e Campos Sulinos. Ministério do Meio Ambiente/Secretaria de Biodiversidade e Florestas, Brasília. 40p.

Mori, S.A.; Mattos-Silva, L.A.; Lisboa, G. \& Coradin, L. 1985. Manual de manejo do herbário fanerogâmico. $2^{a}$ ed. CEPLAC/CEPEC, Ilhéus. 104p.

Queiroz,L.P.; França,F.; Giulietti, A.M.; Melo, E.; Gonçalves, C.N.; Funch, L.S.; Harley, R.M.; Funch, R.R. \& Silva, T.S. 2005. Caatinga. In: Juncá, F.A.; Funch, L. \& Rocha, W. (orgs.). Biodiversidade e conservação da Chapada Diamantina. Biodiversidade 13. Ministério do Meio Ambiente, Brasília. Pp. 95-120.

Ribeiro, J.E.L.S.; Hopkins, M.J.G.; Vicentini, A.; Sothers, C.A.; Costa, M.A.S.; Brito, J.M.; Souza, M.A.D.; Martins, L.H.P.; Lohmann, L.G.; Assunção,
P.A.C.L.; Pereira, E.C.; Silva, C.F.; Mesquita, M.R. \& Procópio, L.C. 1999. Saprófitas. In: Flora da Reserva Ducke: Guia de identificação das plantas vasculares de uma floresta de terra-firma na América Central. INPA, Manaus. P. 84.

Santos, J.C.; Uchôa Neto, C.A.M.; Carneiro, R.S. \& Albuquerque T.C.A. 2001. Diagnóstico das reservas ecológicas da região metropolitana do Recife. Secretaria de Ciência e Tecnologia do Estado de Pernambuco, Recife. 79p.

Souza, V.C. \& Lorenzi, H. 2008. Botânica sistemática: Guia ilustrado para identificação das famílias de fanerógamas nativas e exóticas no Brasil, baseado em APG II. $2^{\mathrm{a}}$ ed. Instituto Plantarum, Nova Odessa. 704p.

Struwe, L. \& Albert, V.A. 2004. Gentianaceae. In: Smith, N.; Mori, S.A.; Henderson, A.; Stevenson, D.Wm. $\&$ Heald, S.V. (eds.). Flowering plants of the Neotropics. Princeton University press, Princeton. Pp. 166-168.

Struwe, L.; Maas, P.J.M.; Pihlar, O. \& Albert, V.A. 1999. Gentianaceae. In: Berry, P.E; Holst, B.K. \& Yatskievych, K. (eds.). Flora of the Venezuelan Guayana. Vol. 5. Missouri Botanical Garden, Saint Louis. Pp. 474-542.

Thiers, B. 2009 [continuously updated]. Index Herbariorum: A global directory of public herbaria and associated staff. New York Botanical Garden's Virtual Herbarium. Disponível em <http://sweetgum.nybg. org/ih/>. Acesso em 07 dezembro 2009.

Trindade, M.B.; Lins-e-Silva, A.C.B.; Silva, H.P.; Figueira, S.B. \& Schessl, M. 2008. Fragmentation of the Atlantic rainforest in the northern coastal region of Pernambuco, Brazil: Recent changes and implications for conservation. Bioremediation, Biodiversity and Bioavailability 2: 5-13.

Uchôa Neto, C.A.M. \& Tabarelli, M. 2002. Diagnóstico e estratégia de conservação do centro de endemismo Pernambuco. CEPAN, Recife. 69p.

Veloso, H.P.; Filho, A.L.R.R. \& Lima, J.C.A. 1991. Classificação da vegetação brasileira adaptada a um sistema universal. CDDI, Rio de Janeiro. 124p.

Lista de exsicatas

Albuquerque, N. 28, 618 (4). Alves, M. 395 (1). Alves-Araújo, A. 189a (1), 189b (2), 480 (4), 527 (6), 529 (1), 530 (2), 666,902 (1). Cano, O. 213 (4). Eugenio, C. 60 (4). Gallindo, F. s.n. IPA 48567 (4). Leão, T. 121 (4). Andrade-Lima, D. 49-287 (7), 552089 (2), 55-2090 (5), 71-6456 (7), 71-6457 (2), IPA 22.268 (4). Lira, O. 60-67 (4), 118-1967 (1). Lucena, M. 191 (4). Melo A. 90, 100 (2), 101 (1), 113 (3), 114 (2), 116 (6), 126 (2), 127 (1), 129 (4), 142, 150 (2), 294 (1), 295 (2), 308 (1), 312 (2), 327 (4),352 (1), 353 (2). Sobral, M. 564 (4). 